\author{
Cecilia Avenatti de Palumbo
}

Universidad Católica de Argentina

\title{
La sonrisa femenina como configuradora de la subjetividad: el tú de la madre y el tú de Beatriz
}

La primacía de la "existencia personal concreta" sobre un pensamiento reductivamente abstracto y esencialista (1) es uno de los lugares donde la literatura se cruza con la "teología de la imagen" en el corpus balthasariano (2). Entre las presencias literarias con las que Balthasar entreteje su pensamiento (3), La Divina Comedia se destaca como lugar donde dicho encuentro se da de modo eminente, inaugural y paradigmático, pues, es precisamente aquí, donde Dante da inicio a un nuevo estilo estético teológico, que hubo de aguardar nueve siglos para revelar su fuerza kairológica (4). Sobre la base de la reconocida centralidad que el topos "masculino-femenino" tiene en la obra de Balthasar (5), profundizaré aquí en la cuestión del "ser de lo femenino" desde la perspectiva epistemológica del "diálogo interdisciplinario entre literatura y teología" (6), a fin de demostrar que la "sonrisa" abre nuevos horizontes a la reflexión sobre el papel de la mujer en la Denkform balthasariana.

(1) Cfr. Balthasar, Hans Urs von, "Dante", en: Gloria. Una estética teológica. 3. Estilos laicales, Madrid, Encuentro, [1962] 1986, 41.

(2) Cfr. Balthasar, Hans Urs von, Gloria. Una estética teológica. 1. La percepción de la forma, Madrid, Encuentro, [ $\left.{ }^{1} 1961\right]$ 1986, 372. Meis, Anneliese, "La mujer en la teología y el género: una crítica constructiva al concepto", en Seminario Literatura y fe, 26-29 de septiembre de 2005, Pontificia Universidad Católica de Chile, Santiago de Chile, 1-5 (ver nota $N^{\circ} 10$ ).

(3) Éste ha sido el tema desarrollado en mi tesis doctoral. Cfr. Avenatti de Palumbo, Cecilia Inés, $L a$ literatura en la estética de Hans Urs von Balthasar. Figura, drama y verdad, pról. de Olegario González de Cardedal, Salamanca, Secretariado Trinitario, 2002.

(4) Cfr. Avenatti de Palumbo, Cecilia Inés, "Lo erótico como estilo en el "viaje" dramático de Dante", en: La literatura en la estética de Hans Urs von Balthasar. Figura, drama y verdad, Salamanca, Ediciones Secretariado Trinitario, 2002, 149-175; "Dante Alighieri: Figura y drama. La Divina Comedia desde la hermenéutica de Hans Urs von Balthasar" y "Dante Alighieri: eros y ágape. Presencias medievales en el pensamiento de Hans Urs von Balthasar: raíces dantescas de la tensión existencial entre estética y dramática", en: Lenguajes de Dios para el siglo XXI. Estética, teatro y literatura como imaginarios teológicos, Juiz de Fora-Buenos Aires, Ediçoes Subiaco-Ediciones de la Facultad de Teología de la Universidad Católica Argentina, 2007, 417-442; "De la envidia a la concordia: en la Divina Comedia de Dante y en Cuatro Cuartetos de T.S. Eliot", en: Actas de III Jornadas Nacionales de Filosofía Medieval, Influencia medieval en el pensamiento contemporáneo, Academia Nacional de Ciencias de Buenos Aires, 2008, CD-Rom, ISBN: 978-987-537-072-2.

(5) Cfr. Schikendantz, Carlos, "Una forma de pensamiento central en la obra de Hans Urs von Balthasar. La reflexión sistemática sobre la mujer y lo femenino", Teología 94 (2007) 523-549.

(6) Para un relevamiento del estatuto epistemológico del diálogo interdisciplinario entre literatura y teología cfr. Barcellos, José Carlos, "Literatura e teologia: perspectivas teórico-metodológicas no 
Mi hipótesis inicial consistió en preguntarme si era posible establecer una vinculación entre la "sonrisa de Beatriz" y la "sonrisa materna" que presenta Balthasar como punto de partida para la configuración de una "metafísica del amor" y de una "teología lúdica" (7). Para dar respuesta a este interrogante, la exposición ha sido dividida en dos partes, en virtud de la relación que existe entre: 1) la "sonrisa" y la apertura al amor personal sexuado que se inaugura para la teología con la figura de Beatriz; 2) la "sonrisa" y el despertar del niño, en un mismo acto lúdico, al amor del tú materno, al asombro metafísico y a la sabiduría de Dios.

\section{PARTE. LA "SONRISA DE BEATRIZ" Y LA HOSPITALIDAD LIBERADORA DEL TÚ}

\section{La sonrisa de Beatriz y el amor entre varón y mujer como "teofanía"}

En la segunda parte de Gloria (8), dedicada a demostrar la eficacia histórica de los estilos estético teológicos como manifestaciones kairológicas de la gloria de Dios (9), Balthasar sitúa en el 1300 el momento de giro de una teología monásticoclerical hacia una teología laica, "paso difícilmente advertido" que realiza justamente la obra de Dante, al proponer "por primera vez en la historia del espíritu cristiano el misterio de un amor eterno de hombre y mujer" (10) como lugar teológico. El alcance de la incorporación de Dante y de su renovación teológica hay que medirlo desde la perspectiva del objeto formal de los estilos, que Balthasar define como "Dios en sî" y "todo lo demás [...] en cuanto expresa y representa a Dios, en cuanto se ilumina a base de Dios y retorna a Dios" (11).

En este marco hermenéutico ha de comprenderse que el autor subraye la "potencia original" con la que Dante afronta el problema del eros cristiano, que resuelve de

pensamento católico contemporâneo", Numen 3/2 (2000) 9-30; "Literatura y teología: perspectivas teórico-metodológicas en el pensamiento católico contemporáneo”, Teología 93 (2007) 253-270; "Literatura e teologia", en: Édson Fernando de Almeida; Luiz Longuini Neto (org.), Teologia para $q u \hat{e}$ ? Rio de Janeiro, Mauad, 2007, 113-128; "Literatura y teología", en Teología 96 (2008) 289-306.

(7) En la bibliografía secundaria no hallamos investigaciones que hayan vinculado genéticamente la "sonrisa de Beatriz" con la "sonrisa" materna". Cfr. Hans Urs von Balthasar Sekundärliteratur: http:// homepage.bluewin.ch/huvbslit/ Stand 18. Juli 2008.

(8) La segunda parte de Gloria, corresponde a los tomos 2 y 3 de la traducción española. Cfr. Balthasar, Hans Urs von, Gloria. Una estética teológica. 2. Estilos eclesiásticos, Madrid, Encuentro, [ $\left.{ }^{1} 1961\right]$ 1986 y Gloria. Una estética teológica. 3. Estilos laicales, Madrid, Encuentro, [1962] 1986.

(9) Para ampliar el concepto balthasariano de estilo estético teológico y su relación con la literatura, cfr. Avenatti de Palumbo, Cecilia Inés, "Lo erótico como estilo en el "viaje" dramático de Dante", en: $L a$ literatura en la estética de Hans Urs von Balthasar. Figura, drama y verdad, Salamanca, Ediciones Secretariado Trinitario, 2002, 139-149; "Teoestética y estilo. Estilo, expresión y cairos en la Estética Teológica de Hans Urs von Balthasar", en: Lenguajes de Dios para el siglo XXI. Estética, teatro y literatura como imaginarios teológicos, Juiz de Fora-Buenos Aires, Ediçoes Subiaco-Ediciones de la Facultad de Teología de la Universidad Católica Argentina, 2007, 104-113.

(10) Balthasar, Hans Urs von, "Introducción", en: Gloria. Una estética teológica. 2. Estilos eclesiásticos, Madrid, Encuentro, [ $\left.{ }^{1} 1961\right]$ 1986, 19.

(11) Balthasar, Hans Urs von, "Introducción”, en: Gloria. Una estética teológica. 2. Estilos eclesiásticos, Madrid, Encuentro, [ $\left.{ }^{1} 1961\right]$ 1986, 23. 
modo arquetípico y único en la "figura femenina de Beatriz" (12). La novedad que representa para la historia de la teología la introducción del amor personal y sexuado como teofanía (13) brota, efectivamente, de la irradiación de la figura de Beatriz, más específicamente de su "sonrisa" y su "mirada" como manifestaciones perceptibles y concretas de su interioridad. La apertura al otro, que obra el tú de Beatriz en el yo cerrado de Dante, la considera Balthasar única en la historia de la literatura, puesto que "sólo ella lleva del eros al ágape o es el eros que se transforma en ágape" (14): "jamás se ha intentado en literatura una cosa semejante ni antes ni después" (15).

\section{La sonrisa de Beatriz como "clave de lectura" del itinerario dantesco}

Pero, ¿quién es Beatriz?, se pregunta el teólogo suizo. ¿Quién es este tú amoroso que logra despertar al yo a la conciencia de saber que el en-sí de su identidad sólo se opera en virtud de la mirada sonriente del tú? ¿Beatriz es eros o ágape? ¿O más bien eros y ágape expresados en y por la misma "sonrisa"? (16) El camino de respuesta a estos interrogantes lo emprende el teólogo suizo a partir de la clave de la “sonrisa". Desde el encuentro melancólico con el Amor-Poesía de la Vita Nuova (17), cuyos ojos y sonrisa la Amada simboliza con atracción irresistible, Balthasar nos conduce a través del puente filosófico del Amor-Sabiduría del Convivio hasta el Amor-Existencial de la Comedia. Si bien la génesis del semblante de Beatriz hunde sus raíces en la retórica platónica del cor gentile del dolce stil nuovo (18), el sentido trágico y la nostalgia (que conserva aún el episodio de Paolo y Francesca) habrá de quedar transfigurado por la gracia del amor agápico existencial y encarnado, que en la Comedia no buscará disolverse ya más en idealizaciones poéticas ni filosóficas.

Mientras en la Vita Nuova la atracción de la sonrisa es de orden ideal, el Convivio acentúa el dinamismo expresivo de la transparencia de lo invisible en lo sensible cuando propone que "'por las ventanas de los ojos' asoman los estados íntimos del alma e igualmente se expresa el alma en la sonrisa de la boca como el color

(12) Balthasar, Hans Urs von, "Introducción”, en: Gloria. Una estética teológica. 2. Estilos eclesiásticos, Madrid, Encuentro, [ $\left.{ }^{1} 1961\right]$ 1986, 21 y 28.

(13) Insiste Balthasar en otorgar a Dante el primer lugar en la incorporación del amor entre varón y mujer dentro de la historia de la teología. Cfr. Balthasar, Hans Urs von, "Dante", en: Gloria. Una estética teológica. 3. Estilos laicales, Madrid, Encuentro, [1962] 1986, 38-39.

(14) Balthasar, Hans Urs von, "Dante", en: Gloria. Una estética teológica. 3. Estilos laicales, Madrid, Encuentro, [1 $\left.{ }^{1} 1962\right]$ 1986, 43.

(15) Balthasar, Hans Urs von, "Dante", en: Gloria. Una estética teológica. 3. Estilos laicales, Madrid, Encuentro, [ [ $\left.{ }^{1} 1962\right]$ 1986, 58.

(16) Para la relación entre eros y ágape cfr. Avenatti De Palumbo, "Eros y ágape: unidad y complejidad de una experiencia”, en: Fernández, Víctor M.-Galli, Carlos M. (dir.) Eros y Ágape. Comentario a Deus Caritas est (Dios es amor), Primera Encíclica del papa Benedicto XVI, Buenos Aires, San Pablo, 2008, 82-97.

(17) De las nueve referencias de Balthasar a la sonrisa de Beatriz, dos están en relación con la Vita Nuova, 3 con el Convivio y las 4 restantes con la Comedia. Cfr. Balthasar, Hans Urs von, "Dante", en: Gloria. Una estética teológica. 3. Estilos laicales, Madrid, Encuentro, $\left[{ }^{1} 1962\right]$ 1986, 46, 48, 51, 52, 52, 55, 59, 70, 85 .

(18) Cfr. Balthasar, Hans Urs von, "Dante", en: Gloria. Una estética teológica. 3. Estilos laicales, Madrid, Encuentro, [1'1962] 1986, 47-48. 
tras el vidrio" (19). Sin embargo, en el Convivio el impulso erótico hacia la sabiduría sigue constituyendo aún un esfuerzo humano. Sólo en la Comedia se invierte el dinamismo del amor por la acción concreta y descendente de la triple mediación femenina María-Beatriz-Lucía, las cuales piden a Virgilio que conduzca a Dante desde la selva oscura hasta la plenitud de la luz de la rosa donde habita Dios.

Los investigadores coinciden en subrayar que la "sonrisa" es el signo distintivo de la originalidad de Dante como poeta cristiano (20). Si bien la risa y la sonrisa, como expresiones de la alegría de vivir, ingresan en el arte cristiano del siglo XIII con Francisco de Asís, el rito de la risa pascual y la sonrisa gótica del ángel de Reims, el gran maestro de la sonrisa es Dante (21). Coincide Balthasar con la crítica en aseverar que "la maravilla más grande de La Divina Comedia es la sonrisa" (22), puesto que en ella "todo sonríe" (23).

\section{La sonrisa de Beatriz como expresión de "singularidad" en la "apertura" al tú}

La "sonrisa" sobre la que posa Balthasar su atención es la sonrisa primera y fundante, no la última. Se trata de la "sonrisa" que expresa la experiencia original del amor, la de la "alegría" ontológica de saberse el yo amado y recibido por un tú, no la sonrisa de la despedida nostálgica. Así se refiere el teólogo suizo a este giro decisivo para la historia de la teología que operó la creatividad del más grande poeta creyente:

"Si los ojos y la sonrisa de la filosofía centelleaban a la vista del Convivio, impulsándole adelante, la Comedia está toda entera traspasada por la mirada y la sonrisa o, mejor, la risa (riso) de Beatriz. [...] Dante interpreta constantemente su viaje como una gracia y como una gracia inconcebiblemente singular y sublime" (24).

¿Risa o sonrisa? Del verbo latino rideo proviene el sustantivo risus y su derivado compuesto subrideo, cuya diferencia literal de significado consiste en la ausencia de ruido que acompaña a subrisus respecto al estruendo sonoro de risus. En esta distinción etimológica reconocemos una doble génesis: en la sonrisa, el movimiento va desde adentro hacia afuera, en la risa, de afuera hacia adentro. De ahí que, aunque etimológicamente ambas acepciones coinciden en ser manifestación de la alegría, hay una diferencia difícil de precisar que consiste en que, mientras en la risa el ser

(19) Cfr. Balthasar, Hans Urs von, "Dante", en: Gloria. Una estética teológica. 3. Estilos laicales, Madrid, Encuentro, [ $\left.{ }^{1} 1962\right]$ 1986, 51.

(20) Cfr. Hawkins, Peter S., "All Smiles: Poetry and Theology in Dante", PMLA: Publications of the Modern Language Association of America 121.2 (Mar. 2006): 371-387, 377.

(21) Cfr. Hawkins, Peter S., "All Smiles: Poetry and Theology in Dante", PMLA: Publications of the Modern Language Association of America 121.2 (Mar. 2006): 371-387, 377.

(22) Moeller, Charles, "El paraíso del reposo y la sonrisa de Dios", en: Sabiduría griega y paradoja cristiana, Madrid, Encuentro, 1989, 255-258, 255.

(23) Hawkins, Peter S., "All Smiles: Poetry and Theology in Dante", PMLA: Publications of the Modern Language Association of America 121.2 (Mar. 2006): 371-387, 371.

(24) Balthasar, Hans Urs von, "Dante", en: Gloria. Una estética teológica. 3. Estilos laicales, Madrid, Encuentro, [ $\left.{ }^{1} 1962\right]$ 1986, 55. 
humano es víctima de un cierto descontrol o desmoronamiento del espíritu de algo que lo provoca desde afuera, el origen de la sonrisa es interior y su epifanía silenciosa es la de un ser que tiene sereno control sobre sí mismo y sobre su expresión (25).

Pues bien, risa y sonrisa aparecen, de modo intercambiable, cerca de setenta veces en la Comedia: dos veces en el Infierno, veinte en el Purgatorio y el resto en el Paraíso (26). Aunque ambas acciones se originan en experiencias de alegría, cabría una distinción en el uso dantesco de una y otra, a saber, que la sonrisa -sobre todo en el Paraíso- es signo de reconocimiento de la "singularidad" personal, ya que no hay una sonrisa igual a la otra.

El amor que se manifiesta en la "sonrisa de Beatriz" no encierra a Dante, sino que lo abre a la sorpresa del tú de la amada. Se trata de la fundación de una subjetividad abierta al otro, no cerrada en sí. En esta apertura consiste la purificación cuyo punto dramático culminante es el encuentro de ambos amantes en el Paraíso Terrenal en la cima del Purgatorio (27). Desde la perspectiva de la sonrisa como apertura al tú, la importancia de esta escena radica en que es justamente aquí donde se produce la transfiguración del eros a secas en eros agápico. El encuentro con la sonrisa es el que libera y abre el yo de Dante al tú de Beatriz y en éste al Tú de Dios (28).

Lo que dimana de la "santa sonrisa" de Beatriz es la fuerza secreta de Dios que, para Balthasar, es la referencialidad última de la "antigua red" (Pur 32,6) y la "antigua llama" (Pur 30, 39-48): antigua en el sentido de primigenia (29). La sonrisa vuelve "hospitalaria" la mirada que aún en su belleza puede resultar distante y hasta hostil. Es la sonrisa la que hace posible la confesión de Dante en el río Leteo y la

(25) Mientras en alemán la diferencia entre "Lachen" (risa) y "Lächeln" (risa pequeña) está signada por la sutileza del tamaño, el inglés señala una diferencia marcada entre "laughter" (risa) y "smile" (sonrisa) que estaría marcada por la correspondencia de "laughter" con la esfera de la naturaleza sin o poco control y la correspondencia de "smile" con la esfera del control muscular. Cfr. Hawkins, Peter S., "All Smiles: Poetry and Theology in Dante", PMLA: Publications of the Modern Language Association of America 121.2 (Mar. 2006): 371-387, 377. De la misma opinión es P. Berger quien citando un estudio de Helmut Plessner sobre la sonrisa dice: "Plessner escribió un breve y elegante ensayo sobre la sonrisa, además de su obra más amplia sobre la risa y el llanto. Destaca la diferencia entre la risa y la sonrisa, a pesar de la relación etimológica que existe entre ambos términos en muchas lenguas, anunque no en inglés (subridere, en latín, sourire, en francés, y términos afines en otras lenguas románicas, todos los cuales denotan todos una "sub-risa": lächeln, en alemán, que significa "risa pequeña"). Si Plessner está en lo cierto, esta etimología resulta engañosa: la sonrisa no sería una subcategoría de la risa, aunque guarde relación con ella y, al igual que en el caso de la risa, podríamos distinguir entre la sonrisa cómica y otras formas del fenómeno. La diferencia esencial reside en que, a diferencia de la risa, la sonrisa es una expresión controlada; no se produce un "desmoronamiento": "En la risa y en el llanto el hombre es víctima de su espíritu; en la sonrisa, lo expresa"”. Berger, Peter, Risa redentora. La dimensión cómica de la experiencia humana, Barcelona, Kairós, 1998, 94.

(26) Hawkins, Peter S., "All Smiles: Poetry and Theology in Dante", PMLA: Publications of the Modern Language Association of America 121.2 (Mar. 2006): 371-387, 378.

(27) Cfr. Balthasar, Hans Urs von, "Dante", en: Gloria. Una estética teológica. 3. Estilos laicales, Madrid, Encuentro, [ $\left.{ }^{1} 1962\right]$ 1986, 61.68.72.

(28) Cfr. Balthasar, Hans Urs von, "Dante", en: Gloria. Una estética teológica. 3. Estilos laicales, Madrid, Encuentro, [1962] 1986, 93.

(29) Cfr. Balthasar, Hans Urs von, "Dante", en: Gloria. Una estética teológica. 3. Estilos laicales, Madrid, Encuentro, [1962] 1986, 60. 
consecuente purificación de una subjetividad cerrada que se abre por acción del amor de Beatriz:

"Nada hay en la Comedia parangonable al vigor de esta escena, que es el punto crucial del poema. El eros ha crecido y madurado más allá de la subjetividad, asumiendo la forma objetiva del sacramento y, viceversa, la forma sacramental eclesial deviene necesaria, justificada y fidedigna como amor. Tenemos aquí la eclesiología en el sentido más moderno de la palabra. Del corazón de la Iglesia irrumpe el amor más personal, pero este amor personal no tolera ninguna subjetividad que no esté purificada, justificada y superada por la subjetividad de Dios mismo y custodiada por ella" (30).

Es el Tú divino el que opera en Beatriz. Es la subjetividad del amor de Dios la que irrumpe para "hospedar" y custodiar la subjetividad humana. El eros ha pasado del amor egoísta e inmaduro (dodim) al amor maduro que se entrega oblativamente (ahabá) (31). Otredad y donación son a partir de la "escena de la confesión" los signos del amor verdadero; por eso, ella no es un episodio más sino "el punto dinámico final de todo el itinerario [...] y, a su vez, el punto de partida al Paraíso" (32). Efectivamente se opera aquí la superación definitiva de la subjetividad por la objetividad del amor. La confesión en el amor y por amor. "Semejante trascendencia del yo angosto y pecaminoso -dice Balthasar-, semejante liberación para el tú y el amor valían la pena todos los sufrimientos y humillaciones" (33).

\section{La "sonrisa" de Beatriz y la "alegría” de la tercera vía del amor cristiano}

"Mujer" de su corazón y "estrella" guía, en el Paraíso "Beatriz es toda ella eterna y bienaventurada "sonrisa", abismo de alegría, del que Dante ve afluir sobre él todas las mociones de su propia bienaventuranza" (34). La "alegría" es, pues, la fuente de la "sonrisa". Se trata de la alegría que proviene de una subjetividad que se ha abierto al otro. Balthasar va más allá cuando afirma que la clave del estado de abierto que provoca el tú de Beatriz es su estar puesta en Dios la mirada:

"Beatriz mira a Dios, Dante mira a Beatriz y comprueba en su purísimo espejo la señal de Dios. Porque la amada no le encierra al poeta en sí mismo, sino que le abre la visión de toda la realidad y se la abre a él, que está tentado a

(30) Balthasar, Hans Urs von, "Dante", en: Gloria. Una estética teológica. 3. Estilos laicales, Madrid, Encuentro, [ $\left.{ }^{1} 1962\right]$ 1986, 68.

(31) Cfr. Avenatti de Palumbo, "Eros y ágape: unidad y complejidad de una experiencia", en: Fernández, Víctor M.-Galli, Carlos M. (dir.) Eros y Ágape. Comentario a Deus Caritas est (Dios es amor), Primera Encíclica del papa Benedicto XVI, Buenos Aires, San Pablo, 2008, 82-97, 88.

(32) Balthasar, Hans Urs von, "Dante", en: Gloria. Una estética teológica. 3. Estilos laicales, Madrid, Encuentro, [1962] 1986, 69.

(33) Balthasar, Hans Urs von, "Dante", en: Gloria. Una estética teológica. 3. Estilos laicales, Madrid, Encuentro, [ $\left.{ }^{1} 1962\right]$ 1986, 93.

(34) Balthasar, Hans Urs von, "Dante", en: Gloria. Una estética teológica. 3. Estilos laicales, Madrid, Encuentro, [ $\left.{ }^{1} 1962\right]$ 1986, 70. 
limitarse exclusivamente a ella, y carece de espíritu y de palabra cuando trata de expresar el amor que irradia de sus ojos santos" (35).

Para Balthasar, no caben aquí ni mitigaciones estéticas ni excusas fatalistas (36): no es ni la vía de la apariencia ni de la vía del combate trágico, sino la tercera vía del amor cristiano (37). Por eso, en la perspectiva estético-teológica la "última sonrisa" de Beatriz (Par 31, 91-93) no puede ser interpretada desde la nostalgia de la apariencia esteticista ni desde la tragicidad del nihilismo, sino desde la plenitud del amor que transfigura (38). "Dante es enemigo de toda actitud faustiana o donjuanesca" (39). Hay una última sonrisa de Beatriz que se despide de Dante, pero no es la suya la última sonrisa de la Comedia. En la rosa de luz sonríe la Virgen María, la Belleza (Par 31, 133-135), sonríen los santos, sonríe la misma Trinidad en el centro de la rosa (Par 33, 124-126). La sonrisa es la forma del amor, y si bien "eros cierra el pacto y abre [...] al infinito, sólo lo hace en cuanto al mismo tiempo cierra. Eros es forma y confiere forma. Nada queda en el fondo sin respuesta, en vaguedades. Lo indefinido debe perfilarse en una forma" (40).

\section{La sonrisa de Beatriz y la "belleza" irradiante del "eterno femenino"}

La "sonrisa" es, pues, la "forma" de la Comedia que perdura como expresión de la objetividad de la luz, la alegría y el amor en la rosa. Es la alegría que produce en el interior del sujeto la liberación plena, alegría sin la cual no hay belleza ni sonrisa (41). De ahí que para Balthasar "la imagen última no es Beatriz sino María. No Dante sino Bernardo quien pronuncia la última palabra y la plegaria última” (42).

El "eterno femenino" - punto de llegada del estudio de Balthasar- está contenido todo él en la "forma del concreto viviente" que es Beatriz. El suelo propio de lo femenino es ser manifestación, "relación expresiva entre el fondo indecible del ser y su autodicción en la forma de ser [que] adquiere un centro humano en la belleza de

(35) Balthasar, Hans Urs von, "Dante", en: Gloria. Una estética teológica. 3. Estilos laicales, Madrid, Encuentro, [1 $\left.{ }^{1} 1962\right]$ 1986, 72.

(36) Cfr. Balthasar, Hans Urs von, "Dante", en: Gloria. Una estética teológica. 3. Estilos laicales, Madrid, Encuentro, $\left[{ }^{1} 1962\right]$ 1986, 61.

(37) Cfr. Balthasar, Hans Urs von, El todo en el fragmento, Madrid, Encuentro, 2008, 70-87.

(38) Cfr. Balthasar, Hans Urs von, "Dante", en: Gloria. Una estética teológica. 3. Estilos laicales, Madrid, Encuentro, [1 $\left.{ }^{1} 1962\right]$ 1986, 85.

(39) Balthasar, Hans Urs von, "Dante", en: Gloria. Una estética teológica. 3. Estilos laicales, Madrid, Encuentro, [ [1962] 1986, 86.

(40) Balthasar, Hans Urs von, "Dante", en: Gloria. Una estética teológica. 3. Estilos laicales, Madrid, Encuentro, [ [1962] 1986, 84.

(41) De similar opinión es Edgar de Bruyne cuando afirma que: "Para Dante como para Escoto la belleza es inconcebible si el rostro por regular y bien coloreado que sea, no expresa sentimientos alegres, de cualquier matiz. De ahí la sonrisa y aun la risa en el rostro esplendente de Beatriz: alegría, regocijo, bienaventuranza. [...] A la sonrisa hay que añadir un brillo luminoso de alma y cuerpo. La risa es el esplendor brillante de un placer interior que irradia su luz hacia fuera". De Bruyne, Edgar, Historia de la estética, $t$. II, Madrid, Biblioteca de Autores Cristianos, 1963, 689-690.

(42) Balthasar, Hans Urs von, "Dante", en: Gloria. Una estética teológica. 3. Estilos laicales, Madrid, Encuentro, [ [1962] 1986, 91. 
Beatriz" (43). Belleza hecha sonrisa, ella es, simultáneamente y en un mismo acto, "eros y ágape, que para Dante son dos nombres de la misma cosa, el Amor, que es el nombre propio de Dios" (44). Este Amor es, entonces, el que sostiene y funda la sonrisa como manifestación de la gratuidad del ser. De la alegría profunda procede el esplendor de la sonrisa. De ahí también que:

"El eterno femenino que atrae aquí a las alturas es mucho más que un mero símbolo, más aún que una alegoría, es la realidad que a todos los niveles, desde el cuerpo tangible y terreno de la mujer amada, pasando por su figura transformada, llega sin interrupción de continuidad hasta santa Lucía, como representante de la ecclesia sanctorum, y a María, como fundamento arquetípico de la Iglesia virginalmente fecunda y fecundamente virginal” (45).

La figura de la belleza-sonrisa es la forma expresiva de la verdad y del bien, el umbral que encierra en sí la "gracia secreta", el "misterio santo" (46), y por ello vía privilegiada de encuentro inmediato con Dios. La belleza es "huella" (47). La "sonrisa de Beatriz" se revela así como figura que "desde" sí opera la transformación del amado "en" la lucha dramática de la confesión de su identidad para conducirlo, de alegría en alegría o bien de sonrisa en sonrisa, "hacia" la verdad de Dios en la figura concreta de la rosa (48).

\section{PARTE. LA “SONRISA MATERNA” Y LA GRATUIDAD DONANTE DEL TÚ}

\section{Sonrisa materna y "singularidad" referencial}

La "sonrisa de Beatriz", que en el cruce de literatura y teología le reveló a Balthasar su fuerza teofánica, atraviesa el corpus del teólogo suizo en su totalidad (49), aunque transmutada en la "sonrisa materna", en cuya singularidad Balthasar

(43) Balthasar, Hans Urs von, "Dante", en: Gloria. Una estética teológica. 3. Estilos laicales, Madrid, Encuentro, $\left[{ }^{1} 1962\right] 1986,111$.

(44) Balthasar, Hans Urs von, "Dante", en: Gloria. Una estética teológica. 3. Estilos laicales, Madrid, Encuentro, [1 $\left.{ }^{1} 1962\right]$ 1986, 111.

(45) Balthasar, Hans Urs von, "Dante", en: Gloria. Una estética teológica. 3. Estilos laicales, Madrid, Encuentro, [ $\left.{ }^{1} 1962\right]$ 1986, 111.

(46) Cfr. Balthasar, Hans Urs von, "Dante", en: Gloria. Una estética teológica. 3. Estilos laicales, Madrid, Encuentro, [ [1962] 1986, 112.

(47) Cfr. Balthasar, Hans Urs von, "Dante", en: Gloria. Una estética teológica. 3. Estilos laicales, Madrid, Encuentro, [ [1962] 1986, 113.

(48) Para la aplicación del método trilógico balthasariano "desde la figura, en el drama, hacia la verdad" a la Comedia, cfr. Avenatti de Palumbo, Cecilia Inés, "Lo erótico como estilo en el "viaje" dramático de Dante", en: La literatura en la estética de Hans Urs von Balthasar. Figura, drama y verdad, Salamanca, Ediciones Secretariado Trinitario, 2002, 149-175.

(49) Sin pretensión de agotar la nómina de textos donde Balthasar se refiere al tema, ofrecemos a continuación una cronología de los que juzgamos los principales lugares de la obra donde aparece mencionada la "sonrisa materna", subrayando la precedencia temporal del estudio sobre Dante. Colocamos entre corchetes el año de la primera edición:

Balthasar, Hans Urs von: 
ve la "huella" que conduce al hombre a la fuente originaria del Ser y del Dios trino. El principal punto de contacto entre ambas "sonrisas" consiste en su condición originaria y configuradora, en la medida en que, por su referencialidad al origen, ambas suscitan la salida de sí del yo hacia la otredad de un tú que dice en el lenguaje gestual de la sonrisa: Es bueno que existas. Quiero que existas porque te amo.

En el horizonte posmoderno de la fragmentación y el desamparo, del desarraigo y la exclusión, se multiplican las resonancias que produce la "sonrisa materna" como forma central del pensamiento de uno de los teólogos más representativos del siglo XX. Si con su interpretación estético teológica de la "sonrisa" de Beatriz, Balthasar abría una nueva orientación para la teología, con la figura de la "sonrisa materna" consuma la incorporación de lo concreto viviente en el seno de la cuestión del ser. Si la eficacia de la primera "sonrisa" de Beatriz había conducido a Dante hasta el seno de la Trinidad sonriente, en la proposición de la "sonrisa materna" como experiencia matriz del encuentro con el Tú divino por el camino del tú humano la maternidad ingresa en la visión teológica del rostro de Dios.

\section{Sonrisa materna y "asombro originario": hacia una "metafísica del amor"}

En la breve síntesis de su pensamiento -con cuya lectura inauguró un congreso sobre su obra realizado en Madrid el 10 de mayo de 1988, un mes y medio antes de su muerte (50)- Balthasar retoma por última vez la asociación sonrisa-madre-ser, que había aparecido por primera vez en 1965, como cierre del volumen quinto de Gloria, justamente, en el capítulo dedicado al "lugar de la gloria" en la metafísica moderna (51). Concebido como una meta-antropología, presenta su pensamiento de fondo bajo la clave de la "sonrisa materna":

1. [11962], "Dante", en: Gloria. Una estética teológica. 3. Estilos laicales, Madrid, Encuentro, 1986, $15-113$.

2. [1963] "La perceptibilidad del amor", en: Sólo el amor es digno de fe, Salamanca, Sígueme, 1988, 68-69.

3. [ $\left.{ }^{1} 1963\right]$ "La palabra como niño", en: El todo en el fragmento, Madrid, Encuentro, 2008, 259-268.

4. [1965] "El milagro del ser y la cuádruple diferencia", en: Gloria. Una estética teológica. 5. Metafísica. Edad Moderna, Madrid, Encuentro, 1986, 563-575.

5. [11967] "Movimiento hacia Dios", en: Ensayos Teológicos III. Spiritus Creator, Madrid EncuentroCristiandad, 2004, 15-48 (ver en particular los capítulos "Del tú humano al Tú divino", 15-21 y "El conocimiento de Dios desde la naturaleza y desde la gracia", 27-41).

6. [1976] "Individuo y comunidad", en: Teodramática 2. El hombre en Dios, Madrid, Encuentro, 1992, 356-367.

7. [ $\left.{ }^{1} 1978\right]$ "El individuo en el mundo", en: Teodramática 3. El hombre en Cristo, Madrid, Encuentro, 1993, 417-422.

8. [1980] "María en la doctrina y la piedad de la Iglesia", en: Ratzinger, Joseph-Balthasar, Hans Urs von, María, Iglesia naciente, Madrid, Encuentro, 2006, 77-81.

9. [1985] "Nacimiento de la palabra", en: Teológica 2. Verdad de Dios, Madrid, Encuentro, 1997, 244-246.

10. [1988] "Intento de resumir mi pensamiento", Communio (E) IV (1988) 284-288, 286.

11. [11988] Si no os hacéis como este niño, Barcelona, Herder, 1989, 9-34.

(50) Cfr. Balthasar, Hans Urs von, Bibliographie 1925-1990, berarbeitet und ergänzt von Cornelia Capol, Johannes Verlag Einsiedeln, Freiburg 1990, № 528, 97.

(51) Cfr. "El milagro del ser y la cuádruple diferencia", en: Gloria. Una estética teológica. 5. Metafísica. Edad Moderna, Madrid, Encuentro, [1 $\left.{ }^{1} 1965\right]$ 1986, 563-575. 
"El hombre no existe más que en diálogo con su prójimo. El niño es evocado a la conciencia de sí mismo por el amor, por la sonrisa de su madre. El horizonte del Ser infinito se abre para él en ese encuentro revelándole cuatro cosas; 1) que él es uno en el amor con su madre al tiempo que no es su madre; 2) que este amor es bueno y, por tanto, todo el Ser es bueno; 3) que este amor es verdadero y, por consiguiente, el Ser es verdadero; 4) que este amor provoca alegría y gozo, y por tanto todo Ser es bello" (52).

Es la primera "sonrisa materna" la que introduce al niño en el camino hacia el encuentro con el ser que se da en el espacio del amor y se revela como un don que es uno, bueno, verdadero y bello. Podríamos trazar aquí un paralelo entre la "sonrisa materna", cuya presencia se reconoce en los efectos de alegría y gozo que provoca, y la "sonrisa de Beatriz" manifestación de la belleza y la alegría del don de Dios: tanto en la una como en la otra es el esplendor de Dios el que refulge. Ambas son caminos hacia Dios: hacia la figura literaria de la rosa la primera, hacia la realidad de Dios, la segunda, tal como aparece en Mysterium Salutis, cuya publicación es inmediatamente posterior al quinto volumen de Gloria, razón por la cual analizaremos ambos textos a la par:

"El niño pequeño despierta a la conciencia de sí por la llamada amorosa de la madre. Este acceder del espíritu a la posesión consciente de sí es un acto de única y simple plenitud, que sólo in abstracto puede desglosarse en distintos aspectos y fases. [...] La risa -y la entrega en general- de la madre se debe interpretar como la respuesta de amor a amor, suscitada por ella en este ser llamado del yo por el tú. [...] en este yo-tú está básicamente alumbrada la plenitud de la realidad (como en el paraíso), y todo lo que después se puede experimentar como desengaño, deficiencia y ardiente nostalgia tiene en ello su origen exclusivo, por eso todo recibe de este fogonazo originario -el yo, el tú y el mundo- una irradiación tan nítida y tan pura que implica asimismo una apertura de Dios. En el principio existía la Palabra, con la que un tú amante llamó al yo: en el acto de escuchar se halla implícita, previamente a toda reflexión, la capacidad de responder. El niño no recapacita sobre si quiere contestar a la incitadora risa de la madre con amor o desamor, pues así como el sol anima a crecer a la vegetación, así también el amor despierta amor. En el movimiento hacia el tú, el yo se descubre a sí mismo. Al darse, experimenta: yo me doy. Al pasar de sí a lo otro, al mundo ancho y abierto, vive y experimenta su libertad, su capacidad cognoscitiva, su ser espiritual. [...] El espacio y el mundo no existen por la gracia del yo, sino por la gracia del tú (53).

Podemos aquí reconocer en la "sonrisa materna" una dimensión estética, en tanto es "llamada" del tú que sale de sí y atrae al yo del niño para darle cobijo y

(52) Balthasar, Hans Urs von, "Intento de resumir mi pensamiento", Communio (E) IV (1988) 286 (El resaltado es nuestro).

(53) Balthasar, Hans Urs von, "Movimiento hacia Dios", en: Ensayos Teológicos III. Spiritus Creator, Madrid Encuentro-Cristiandad, [1967] 2004, 15-16. 
amparo; una dimensión dramática, en tanto es "respuesta" del yo que despierta a sí mismo en el tú humano y divino realizando la experiencia de la herida ontológica que lo separa del origen y, finalmente, una dimensión lógica en tanto la experiencia de la sonrisa es la base de todo "reconocimiento" del don del amor como horizonte último de la verdad de sí, del mundo y de Dios. Este "acto de única y simple plenitud" coincide con el "asombro primigenio" (Ur-Wunder) que no es sólo punto de partida sino objeto de "admiración" (Bewunderung) permanente, cuya fase inicial acontece en el encuentro con la "primera sonrisa materna". La pregunta por la diferencia ontológica - ¿por qué hay algo en vez de nada?- la reformula Balthasar desde la perspectiva del reconocimiento de la identidad en el amor -¿por qué me ha tocado precisamente a mí?-:

"Ciertamente el niño no despierta a la conciencia con esta pregunta. Y, sin embargo, ella está presente, desconocida pero vigilante y clara, en el primer parpadeo de su espíritu. Su yo brota en la experiencia del tú: con la sonrisa de la madre, gracias a la cual él experimenta que se encuentra insertado, afirmado, amado en algo que incomprensiblemente lo rodea, algo real, y que lo guarda y alimenta. [...] El despertar de su conocimiento es algo tardío en comparación con este misterio abisal que lo precede en una perspectiva incalculable" (54).

Cada niño "empieza" en el mismo asombro absoluto, "conoce" el amor en la seguridad absoluta del cobijo materno y en esta experiencia "concibe" su palabra como respuesta (55). A una pregunta concreta le cabe, pues, una respuesta concreta y vital, que brota de la experiencia infantil de ser amado, recibido y cuidado por el tú de la madre. En este reconocimiento "no se trata de una conducta accidental concreta (ésta ya presupone de por sí al sujeto), sino de la constitución de la "sustancia" sujeto propiamente tal" (56). El proceso de desvelamiento de la subjetividad encuentra su consumación en el lenguaje, puesto que, "la sonrisa de la madre es la primera palabra que lo aborda [al niño] y que él entiende con todo su ser: mediante el lenguaje del amor, es iniciado en el misterio del lenguaje en general: este lenguaje lo entiende mucho antes de aprender a balbucear palabras inconexas" (57).

\section{Sonrisa materna y "raíz trinitaria” de la subjetividad personal}

"La "llamada de la madre [...] en cierta medida actúa como sustituto de la llamada de Dios" (58). La responsabilidad de la madre es muy grande, pues esta "zona

(54) Balthasar, Hans Urs von, Gloria. Una estética teológica. 5. Metafísica. Edad Moderna, Madrid, Encuentro, [1965] 1986, 565.

(55) Cfr. Balthasar, Hans Urs von, El todo en el fragmento, Madrid, Encuentro, 2008, 268.

(56) Balthasar, Hans Urs von, "Movimiento hacia Dios", en: Ensayos Teológicos III. Spiritus Creator, Madrid Encuentro-Cristiandad, 2004, 39-40.

(57) Balthasar, Hans Urs von, "Movimiento hacia Dios", en: Ensayos Teológicos III. Spiritus Creator, Madrid Encuentro-Cristiandad, 2004, 34-35; "Nacimiento de la palabra", en: Teológica 2. Verdad de Dios, Madrid, Encuentro, 1997, 244-246.

(58) Cfr. Balthasar, Hans Urs von, "Movimiento hacia Dios", en: Ensayos Teológicos III. Spiritus Creator, Madrid Encuentro-Cristiandad, 2004, 32. 
imaginaria" y "originariamente santa" es una "zona desamparada" que se encuentra amenazada porque "el niño es débil" (59). Cuidado y cobijo le ofrecen al niño la madre y el padre: la primera en lo inmediato y concreto, el segundo en la provisión del futuro, de modo tal que uno y otro confluyen "en la esfera originaria del bien concreto en la que ambos están unidos al niño" (60).

Por todo lo cual, en la "metafísica del amor" que propone Balthasar, la "sonrisa materna" no sólo descubre al yo su unidad subjetiva en sentido antropológico, sino que también abre el yo al sentido teológico de ser persona, en la conciencia de que en el don (Gabe) se encuentra ya el regalo de la misión (Aufgabe), sentido que se inicia en la interpelación del niño por un tú (61) En el tomo tercero de su Teodramática apela a esta experiencia primordial para afirmar la singularidad inalienable de ser personaje teológico. Como bien lo señala A. Meis, ante el peligro de la abstracción Balthasar propone mantener viva la raíz cristológica y trinitaria de la persona:

"Ser persona designa, entonces, aquel "modo de existir" finito, regalado, que hace suyo libremente el ser regalado, que a su vez remonta al amor absoluto entre el Padre, Hijo y Espíritu Santo con su amado-amante-desbordante, siempre singular y concreto. [...]

El hombre no es persona, de una vez por todas, sino se hace tal, paso a paso, a través de una novedad cada vez mayor, que culmina en el gozo sempiterno de poder ser yo mismo en un perderme sin fin, una intelección de la singularidad concreta posible, si se considera el concepto de persona a partir de su origen trinitario" (62).

En la "sonrisa materna" fulgura la promesa de un amor absoluto que se presenta como un "relámpago" de luz plena, tras el cual sobreviene el "crepúsculo" y la "noche cerrada", pues toda experiencia posterior es una "sustracción" que provoca una decepción fundamental en la medida en que no responde a esta primera intuición. Precisamente por ello, esta "experiencia original del ser como plenitud, alegría y libertad" se presenta como "salvadora de la angustia" en la medida en que "exige y contiene el sí ilimitado" (63).

(59) Cfr. Balthasar, Hans Urs von, Si no os hacéis como este niño, Barcelona, Herder, 1989, 14-15.

(60) Balthasar, Hans Urs von, Si no os hacéis como este niño, Barcelona, Herder, 1989, 27.

(61) Cfr. Balthasar, Hans Urs von, Teodramática 3. El hombre en Cristo, Madrid, Encuentro, 1993, 418419.

(62) Meis W., Anneliese. "La persona como singularidad concreta en la obra de Hans Urs von Balthasar", Teol. vida. [online]. 2001, vol. 42, no. 4 [citado 08 Mayo 2008], p. 440-467. Disponible online en www: <http://www.scielo.cl/scielo.php?script=sci_arttext\&pid=S0049-34492001000400003\&lng= es\&nrm=iso $>$. ISSN 0049-3449.

(63) Balthasar, Hans Urs von, "Movimiento hacia Dios", en: Ensayos Teológicos III. Spiritus Creator, Madrid Encuentro-Cristiandad, 2004, 29-30. 


\section{Sonrisa materna y "juego" de amor y gratitud}

Este encuentro originario y fundante es presentado por Balthasar como juego de amor que consiste en que, recibido en el amor como un don gratuito, el niño responde al tú materno con la gratitud de su propia sonrisa:

"El niño juega porque este ser libremente acogido es lo primero de todo que él experimenta en el dominio del ser. El es en cuanto que se le permite ser como algo amado. Existir es tan maravilloso como evidente. Todo, absolutamente todo lo que podría y deberá añadirse después, será explicitación de esta primera experiencia. No hay ninguna seriedad de la vida que pueda sobrepasar este comienzo. No hay ninguna "asunción administrativa" de la existencia que la pueda hacer avanzar más allá de esta primera experiencia de asombro y de juego. No hay ningún encuentro -con amigos o enemigos o millares de indiferentes- que pueda añadir algo al encuentro con la primera sonrisa de la madre. "Si no os hacéis como niños, no entraréis en el reino de los cielos": esta frase es una tautología. La experiencia primera contiene ya lo insuperable, id quo maius cogitari non potest" (64).

Es esta experiencia primera la que conduce al niño a concebir la "existencia como juego". "Sonrisa y juego" son las dos expresiones concretas del suelo ontológico del ser como "amor y alegría". El juego es la respuesta del niño que evoca la existencia feliz perdida cuya reconquista anhelamos. "Aquí acontece el milagro de que, un día, el niño reconozca en el rostro de la madre su amor protector y le responda con su primera sonrisa" (65). Así, la respuesta que el niño da a la madre es la de la gratitud de su propia "sonrisa" (66). La respuesta a la "misión" es concebida en el fondo como un juego (67). La dimensión lúdica está estrechamente relacionada con la otredad. Por ello señala Balthasar en un texto dedicado a María: "en la sonrisa [de la madre] comprende [el niño] que hay un mundo en el que él es acogido, en el que es bienvenido" [...], lo cual le permite abrirse a la solidaridad de "ser-con" los otros prójimos (68).

Juega el niño y juega Dios cuando crea y redime con "sonriente" misericordia: "En [el juego] el niño crea libremente su mundo. Y la sabiduría creadora de Dios se vuelve, según sus mismas palabras, niño: en efecto, cuando el Padre trabaja en la obra creadora, "jugaba todo el tiempo en su presencia, jugaba con la esfera de la tierra" y así "yo era su alegría cotidiana" (Pr 8, 27-31)" (69). El juego creador y redentor de Dios pertenece al tipo de juego que los niños crean por cuenta propia, sin reglas pre-

(64) Balthasar, Hans Urs von, Gloria. Una estética teológica. 5. Metafísica. Edad Moderna, Madrid, Encuentro, [ $\left.{ }^{1} 1965\right]$ 1986, 566.

(65) Balthasar, Hans Urs von, Si no os hacéis como este niño, Barcelona, Herder, 1989, 22.

(66) Cfr. Balthasar, Hans Urs von, Si no os hacéis como este niño, Barcelona, Herder, 1989, 63-69.

(67) Balthasar, Hans Urs von, Si no os hacéis como este niño, Barcelona, Herder, 1989, 47-48.

(68) Balthasar, Hans Urs von, "María en la doctrina y la piedad de la Iglesia", en: Ratzinger, JosephBalthasar, Hans Urs von, María, Iglesia naciente, Madrid, Encuentro, 2006, 80-81.

(69) Balthasar, Hans Urs von, El todo en el fragmento, Madrid, Encuentro, 2008, 263. A continuación del párrafo citado Balthasar remite en nota al estudio de Rahner, Hugo, El hombre lúdico, Valencia, 
vias, en el que ellos son a la vez "directores y espectadores fascinados, abrumados por el placer de su propia invención y entusiasmados por la originalidad de las leyes que ellos han inventado" (70).

\section{La "sonrisa de Dios" como última referencialidad: hacia una "teología lúdica"}

En esta "teología lúdica" resuenan los ecos de la "sonrisa de Beatriz", puesto que para Balthasar la "sonrisa de Dios" es la manifestación de "la sabiduría divina, que nos mira y sonríe" (71). En la Comedia, la sonrisa que había salido de Dios vuelve a Dios entre cantos y danzas. La Trinidad es esa "sonrisa de Dios" que vive contemplándose, amándose y sonriéndose: "¡Oh luz eterna, que sólo en Ti resides / y sola Te comprendes, y que comprendiéndote / y por Ti comprendida, Te amas y sonríes!" (Par XXXIII, 124-126).

La referencialidad de la "sonrisa de Beatriz" y de la "sonrisa materna" a la "sonrisa de Dios" que hemos probado atraviesa el corpus balthasariano, se integra a las perspectivas teológicas que proponen pensar la alteridad no como la del "otro hostil", sino como la del "tú hospitalario" (72). La mirada vigilante y controladora que hemos fabricado de Dios no constituye sino que destruye; en cambio, la "sonrisa de Dios" es la que, manifestando su ser más propio como ser de amor, inicia el juego libre de dejar en libertad al tú, lo cual supone respetarlo en su insondable misterio de su singularidad creatural (73). De este modo, la sonrisa transforma la mirada otorgándole a ésta el brillo de la acogida amorosa que es la expresión de la belleza. Esta "sonrisa de Dios" es la que, para Balthasar, sostiene con ternura el juego del mundo en el que Él no es un espectador -como sucedía en las teogonías antiguas- sino autor, actor y director pues en este juego se ha implicado su amor (74). Si, como señala Bruno Forte, la cuestión del otro es la cuestión "por la cual se mide la crisis que el Occidente vive y donde se abren las posibilidades para superar aquella extrañeza en la cual nos encontramos" (75), escuchar la voz de Dante y la de Balthasar interpretando a Dante nos hace ingresar en el "juego de la sonrisa", desde el que se nos abre un posible camino para salir de la extrañeza hostil del otro hacia el ancho mundo de la acogida hospitalaria del tú.

Edicep [ ${ }^{1} 1948$ ] 2002. La misma imagen del Dios que juega es retomada por el autor en la relación trinitaria, cfr. en Si no os hacéis como este niño, Barcelona, Herder, 1989, 47.

(70) Cfr. Balthasar, Hans Urs von, El todo en el fragmento, Madrid, Encuentro, 2008, 263.

(71) Balthasar, Hans Urs von, "Dante", en: Gloria. Una estética teológica. 3. Estilos laicales, Madrid, Encuentro, [ $\left.{ }^{1} 1962\right]$ 1986, 52. cfr. Moeller, Charles, "El paraíso del reposo y la sonrisa de Dios", en: Sabiduría griega y paradoja cristiana, Madrid, Encuentro, 1989, 255-258, 257.

(72) Cfr. Gesché, Adolphe, "La identidad como confrontación con Dios", en: El sentido. Dios para pensar VII, Salamanca, Sígueme, 2004, 57-90.

(73) Cfr. Gesché, Adolphe, "La teología como antropología de la revelación” y "La teología como antropología de la revelación”, en: El sentido. Dios para pensar VII, Salamanca, Sígueme, 2004, 177-198.

(74) Habría que convocar su entera Teodrámatica como testigo de esta afirmación esencial. Como lugares centrales para la comprensión del autoimplicarse de Dios en la historia humana en categorías teatrales. Cfr. Balthasar, Hans Urs von, Teodramática 1. Prolegómenos, Madrid, Encuentro, [191990] 1973, 251-331; Teodramática 4. La acción, Madrid, Encuentro, [1'1980] 1995, 295-396.

(75) Cfr. Forte, Bruno, "Introducción", en: A la escucha del otro, Salamanca, Sígueme, [19195] 2005, $9-15,12$. 
“Todo juego en la esencia de su ser, no es más que un baile, una danza alrededor de la verdad", dice Hugo Rahner (76). Sonrisa y juego, sonrisa y gracia, sonrisa y alegría ontológica, sonrisa y danza. La sabiduría divina consiste en jugar el juego de la misericordia, que sólo juega quien se ha vuelto también un niño. Cada vez que un ser humano redimido se convierte nuevamente en niño, el amor baila: una tristeza más queda atrás y una nueva sonrisa se incorpora como expresión de alegría, hasta que incorporados todos a la danza última, "el final [sea] como el principio: el eterno ser del niño" (77).

\title{
RESUMEN
}

El objetivo de este artículo es demostrar que el ser de lo femenino ocupa un lugar eminente en la configuración epistemólógica del diálogo interdisciplinario entre literatura, estética y teología, llevado a cabo por Hans Urs von Balthasar. La vinculación causal entre la dantesca sonrisa de la Beatriz y la sonrisa materna da origen al desarrollo de su metafísica del amor y su teología lúdica. De este modo, metafísica y femineidad, literatura y teología quedan unidas en el misterio de la sonrisa humana.

Palabras clave: Balthasar, Dante, sonrisa materna, teología lúdica, metafísica del amor, hospitalidad, otredad.

\begin{abstract}
The objective of this article is to demonstrate that the being of the feminine occupies an eminent place in the epistemological configuration of interdisciplinary dialogue among literature, esthetics and theology carried out by Hans Urs von Balthasar. The causal relationship between the Dantesque smile of Beatrice and the maternal smile reveals the source of the development of his metaphysics of love and of his ludic theology. In this way, metaphysics and femininity, literature and theology remain united in the mystery of the human smile.
\end{abstract}

Key words: Balthasar, Dante, Maternal smile, Ludic theology, Metaphysics of love, Hospitality, Otherness.

(76) Rahner, Hugo, El hombre lúdico, Valencia, Edicep, [ [ $\left.{ }^{1} 1948\right]$ 2002, 76.

(77) Rahner, Hugo, El hombre lúdico, Valencia, Edicep, [ [1948] 2002, 74. 
